STUDY OF CORONARY OSTIA IN PRESERVED HUMAN CADAVERIC HEART SPECIMENS IN WESTERN MAHARASHTRA BY DISSECTION METHOD

\title{
Dakhane Prafulla S ${ }^{1}$, Patil Tushar $\mathbf{R}^{* 2}$.
}

${ }^{1}$ Associate Professor, Dept. of Anatomy, Dr. Ulhas Patil Medical College, Jalgaon Kh, India.

${ }^{* 2}$ Assistant Professor, Dept. of Anatomy, Dr. Ulhas Patil Medical College, Jalgaon Kh, India.

\section{ABSTRACT}

Introduction: Coronary artery disease is responsible for $70 \%$ cases of sudden cardiac deaths. Small coronary ostia may cause significant difficulty in canulation of it during diagnostic and therapeutic procedures. High origin of coronary arteries increases risk of myocardial ischaemia and sudden death. Considering these significance of variations of coronary ostia in cardiac procedures, detailed study was undertaken so it would be of use to cardiologists and interventional radiologists.

Material and Methods: Sample size for the study comprised of 50 human cadaveric heart specimens. Dissection method was adopted.

Observation and Results: In anterior aortic sinus, 41 specimens had single ostium, while 09 specimens showed two separate ostia. The mean of ostium diameter of right coronary artery was found to be $2.84 \mathrm{~mm}$ with a standard deviation (S.D.) of $+0.85 \mathrm{~mm}$. The mean distance of main ostium of right coronary artery from supravalvular ridge was found to be $1.23 \mathrm{~mm}$. with a S.D. of $+0.32 \mathrm{~mm}$. In case of accessory ostia in anterior aortic sinus, the mean diameter was found to be $1.32 \mathrm{mms}$. with a S.D. of $+0.20 \mathrm{mms}$. The mean distance of these ostia from supravalvular ridge was found to be $1.16 \mathrm{mms}$. with a S.D. of $+0.17 \mathrm{mms}$. In left posterior aortic sinus, 49 specimens had single ostium, while 01 specimen had two separate ostia. This ostium was $0.8 \mathrm{mms}$. in diameter at a distance of $02 \mathrm{mms}$. below from supravalvular ridge. The mean of ostium diameter of left coronary artery was found to be $3.31 \mathrm{~mm}$ with a S.D.of $+0.52 \mathrm{~mm}$. The mean distance of main ostium of left coronary artery from supravalvular ridge was found to be $1.40 \mathrm{~mm}$. with a S.D. of $+0.27 \mathrm{~mm}$.

Conclusion: the study provides data on coronary morphometry and topography. It provides basis for understanding the normal variants for determining incidence of anomalies and for evaluating value of screening of such anomalies.

KEY WORDS: Coronary Ostia, Cardiac Deaths, Anterior Aortic Sinus, Cardiac Procedures, Cadaveric Heart.

Address for Correspondence: Dr. Patil Tushar R, Assistant Professor, Dept. of Anatomy, Dr. Ulhas Patil Medical College, Jalgaon Kh, India. E-Mail: tusharpatil131@gmail.com

Access this Article online Quick Response code

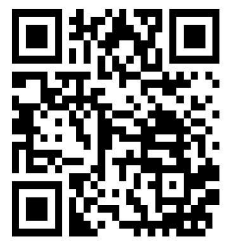

DOI: $10.16965 /$ ijar.2018.216

Journal Information

International Journal of Anatomy and Research

ICV for 2016 ISSN (E) 2321-4287 | ISSN (P) 2321-8967

https://www.ijmhr.org/ijar.htm

DOI-Prefix: https://dx.doi.org/10.16965/ijar

\section{Article Information}

Received: 05 Apr 2018

Peer Review: 06 Apr 2018

Revised: None
Accepted: 30 May 2018

Published (O): 05 Jul2018

Published (P): 05 Jul 2018

\section{INTRODUCTION}

Coronary artery disease is one of the major cause of death in developed countries. The incidence of coronary artery disease is increasing today in developing countries as well, because of changing life style, urbanization, sedentary nature of work, hypertension, diabetes mellitus and increased type A personality. Coronary artery disease is responsible for over $70 \%$ of sudden cardiac deaths. In the young, the primary cause of death is non atherosclerotic coronary abnormalities [1]. 
Coronary ostia are the small openings in the aortic sinuses which give origin to coronary arteries. Coronary arteries supply myocardium. The size and relative position of ostia in regards with supravalvular ridge is clinically important. Small coronary ostia may cause significant difficulty in canulation of it during diagnostic and therapeutic procedures.

The high origin of coronary arteries increases risk of myocardial ischaemia and sudden death due to oblique passage of coronary artery through aortic wall. Study of coronary ostia is helpful for choice of approach for aortic root surgeries [2].

Detail study of coronary ostia would be of use to cardiologists and interventional radiologists to predefine abnormalities by invasive and noninvasive studies. Considering this significance of variations of coronary ostia in cardiac procedures, the present study was undertaken.

\section{MATERIAL AND METHODS}

The heart specimens for this study were obtained from Department of Anatomy, Dr. D.Y. Medical College and Hospital, Kolhapur. The sample size of the study comprised of 50 heart specimens.

Inclusion Criteria: Normal hearts with age groups 20-70 years of both sexes.

Exclusion Criteria: Hearts weighing more than $370 \mathrm{gms}$. in males and $280 \mathrm{gms}$. in females were excluded. Heart specimens in cadavers of age more than 70 yrs. and less than 20 years were excluded. Grossly abnormal hearts were also excluded.

Materials used: Gloves, Dissection box, Magnifying lens, Vernier caliper, Camera

Methods: After opening the thorax, the pericardial cavity is opened, the great vessels are ligated and the specimen of heart along with great vessels is removed from the thoracic cage. Specimen is preserved in $10 \%$ formaldehyde solution. The vertical incision was taken in aortic root extending from ascending aorta above to vestibule of left ventricle below.

The number, diameter and position of coronary ostia with respect to supravalvular ridge were noted with a vernier caliper in millimeters, and readings were tabulated. Data obtained is statistically analysed.

Aim and objective: The present study was aimed at

1. Number (No.) of ostia in each aortic sinus

2. Diameter of each ostia

3. Distance of each ostia from supravalvular ridge

\section{OBSERVATION AND RESULTS}

Fig. 1: Multiple Ostia below Supravalvular Ridge.

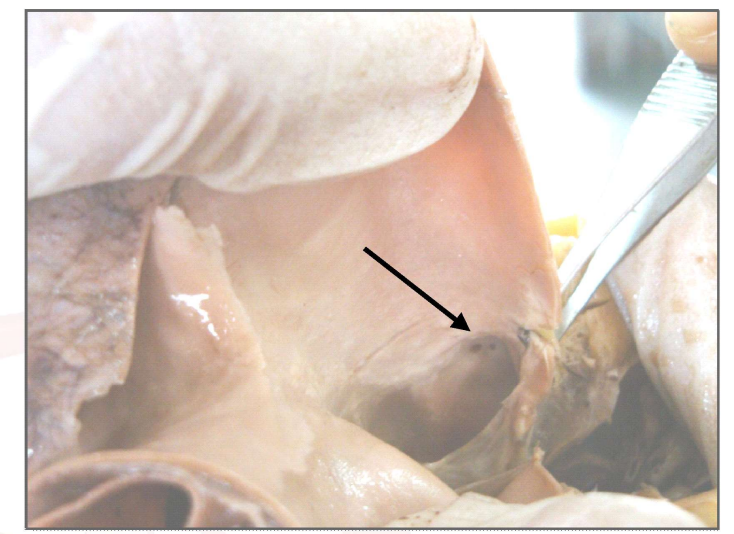

Fig. 2: Single Small Ostium below Supravalvular Ridge.

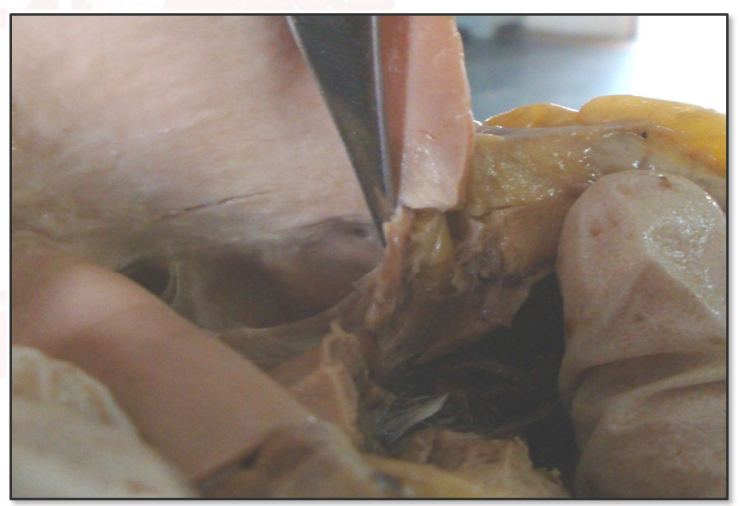

Fig. 3: Single Large Ostium at Supravalvular Ridge.

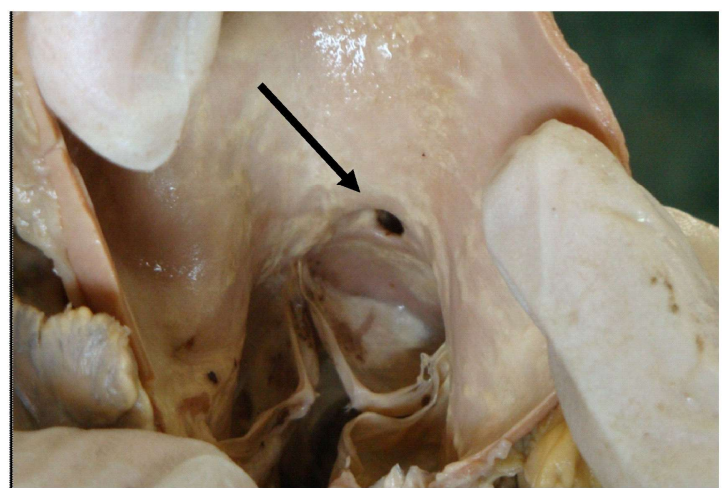

Table 1: Table showing number of ostia in anterior aortic sinus.

\begin{tabular}{|c|c|c|}
\hline Number of Ostia & $\begin{array}{c}\text { No. of } \\
\text { Specimens }\end{array}$ & Percentage \\
\hline One & 41 & $82 \%$ \\
\hline Two & 9 & $18 \%$ \\
\hline Three or More & -- & -- \\
\hline
\end{tabular}


In anterior aortic sinus, 41 specimens had single ostium, while 09 specimens showed two separate ostia. Double ostia were noted in $18 \%$ of specimens.

The right coronary ostium was present in all the specimens in the right anterior aortic sinus. In $96.00 \%$ of the specimens the ostium was below the supravalvular ridge and in $04.00 \%$ of the cases, the ostium was at the supravalvular ridge.

Table 2: Table showing measurement of right coronary ostium diameter, distance from supravalvular ridge in milimetres.

\begin{tabular}{|c|c|c|c|}
\hline Parameter & Range & Mean & S. D. \\
\hline Ostium Diameter & $1.3-05$ & 2.84 & 0.85 \\
\hline $\begin{array}{c}\text { Distance From } \\
\text { Supravalvular Ridge }\end{array}$ & $0-1.7$ & 1.23 & 0.32 \\
\hline
\end{tabular}

The mean of ostium diameter of right coronary artery was found to be $2.84 \mathrm{~mm}$ with a standard deviation (S.D.)of+ $0.85 \mathrm{~mm}$.

The mean distance of main ostium of right coronary artery from supravalvular ridge was found to be $1.23 \mathrm{~mm}$. with a S.D. of $+0.32 \mathrm{~mm}$.

Table 3: Table showing measurement of accessory ostium diameter, distance from supravalvular ridge in milimetres.

\begin{tabular}{|c|c|c|c|}
\hline Parameter & Range & Mean & S. D. \\
\hline Ostium Diameter & $1.0-1.7$ & 1.32 & 0.2 \\
\hline $\begin{array}{c}\text { Distance From } \\
\text { Supravalvular Ridge }\end{array}$ & $0.9-1.4$ & 1.16 & 0.17 \\
\hline
\end{tabular}

In case of accessory ostia in anterior aortic sinus, the mean diameter was found to be 1.32 mms. with a S.D. of $+0.20 \mathrm{mms}$. The mean distance of these ostia from supravalvular ridge was found to be $1.16 \mathrm{mms}$. with a S.D. of +0.17 $\mathrm{mms}$

Table 4: Table showing number of ostia in left posterior aortic sinus.

\begin{tabular}{|c|c|c|}
\hline Number of Ostia & $\begin{array}{c}\text { No. of } \\
\text { Specimens }\end{array}$ & Percentage \\
\hline One & 49 & $98 \%$ \\
\hline Two & 1 & $2 \%$ \\
\hline Three or More & -- & -- \\
\hline
\end{tabular}

In left posterior aortic sinus, 49 specimens had single ostium, while 01 specimen had two separate ostia. This ostium was $0.8 \mathrm{mms}$. in diameter at a distance of $02 \mathrm{mms}$. below from supravalvular ridge. Double ostia were noted in $02 \%$ of specimens.

The ostium of the left coronary artery was present in the left posterior aortic sinus. In $100 \%$ of the cases, the ostium was present below the supravalvular ridge.

Table 5: Table showing measurement of left coronary ostium diameter, distance from supravalvular ridge in milimetres.

\begin{tabular}{|c|c|c|c|}
\hline Parameter & Range & Mean & S. D. \\
\hline Ostium Diameter & $2.1-4.2$ & 3.31 & 0.52 \\
\hline $\begin{array}{c}\text { Distance From } \\
\text { Supravalvular Ridge }\end{array}$ & $0.9-1.8$ & 1.4 & 0.27 \\
\hline
\end{tabular}

The mean of ostium diameter of left coronary artery was found to be $3.31 \mathrm{~mm}$ with a S.D.of+0.52 mm.

The mean distance of main ostium of left coronary artery from supravalvular ridge was found to be $1.40 \mathrm{~mm}$. with a S.D. of $+0.27 \mathrm{~mm}$.

Table 6: Table showing the mean of right coronary and left coronary main ostium diameter, distance from supravalvular ridge, measurements with standard deviation and test of significance.

\begin{tabular}{|c|c|c|c|c|c|c|}
\hline \multirow{2}{*}{ Parameter } & \multicolumn{2}{|c|}{ R.C.A. } & \multicolumn{2}{c|}{ L.C.A. } & T & P \\
\cline { 2 - 5 } & MEAN & S.D. & MEAN & S.D. & Value & Value \\
\hline Ostium Diameter & 2.84 & 0.85 & 3.31 & 0.52 & 3.33 & 0.0012 \\
\hline $\begin{array}{c}\text { Distance From } \\
\text { Supravalvular Ridge }\end{array}$ & 1.23 & 1.23 & 1.4 & 0.27 & 2.84 & 0.0055 \\
\hline
\end{tabular}

The ostium diameter of L.C.A.was larger than the right coronary artery .P value is 0.0012.It is statistically significant.

The orifice of right coronary artery was nearer to the supravalvular ridge than the left coronary artery. The $P$ value is 0.0055 . It is statistically significant.

\section{DISCUSSION}

Usually all the vessels in the body show variability. The coronary arteries also show wide variations among different populations. These structural variations concerning the site of origin, length, diameter, course and branching pattern are of paramount clinical significance. Several studies have been conducted by various authors on origin of coronary artery and found many variations.

Usually right coronary artery originates from single anterior aortic sinus and left coronary artery originates from single left posterior aortic sinus. As often seen in literature, multiple ostia may also be present giving rise to various arteries like conus artery, SA nodal artery and third coronary artery. 
Table 7: Table Showing Comparison of no. of Ostia in aorta (IN PERCENTAGE)

\begin{tabular}{|c|c|c|}
\hline \multirow{2}{*}{ Studies [3] } & \multicolumn{2}{|c|}{ No. Of Ostia } \\
\cline { 2 - 3 } & Two & Three \\
\hline Blake HU et al & $50-77$ & $23-50$ \\
\hline Gajbe UL et al & 83.33 & 6.67 \\
\hline Joshi SD et al & 61.91 & 29.52 \\
\hline Kalpana R et al & 76 & 24 \\
\hline Saidi HS et al & 98 & 2 \\
\hline Thakare GD et al & 95.62 & 4.38 \\
\hline Present Study & 80 & 20 \\
\hline
\end{tabular}

In the present study, two ostia for origin of two coronary arteries were noted in $80 \%$ of specimens, while in remaining $20 \%$ of specimens showed three ostia. Findings of the present study corroborates very much with the findings of authors like Blake HU et al, Joshi SD et al, Kalpana $\mathrm{R}$ et al [3]. Lesser incidence of multiple ostia is also common and noted by authors like Gajbe et al $^{3}$, Saidi et al \& Thakare et al [3].

Size of coronary ostia also plays remarkable role in ease of canulation in various cardiac procedures. The ostium diameter is studied by many authors till date.

Table 8: Table Showing Comparison of Mean Diameter of Ostia of Right \& Left Coronary Artery in Milimeters.

\begin{tabular}{|c|c|c|}
\hline Studies & $\begin{array}{c}\text { Mean diam. of } \\
\text { ostium of R.C.A. }\end{array}$ & $\begin{array}{c}\text { Mean diam. of } \\
\text { ostium of L.C.A. }\end{array}$ \\
\hline Kohler et al [4] & 3.83 & 4.83 \\
\hline Bhimalli et al [5] & 2.38 & 3.17 \\
\hline Dalbir Kaur et al [4] & 3.9 & 4.6 \\
\hline JS Cavalcanti et al [6] & 3.46 & 4.75 \\
\hline Present Study & 2.83 & 3.31 \\
\hline
\end{tabular}

Mean diameter of ostia of right coronary artery ranged from $2.38-3.9 \mathrm{~mm}$. in various studies conducted across the world. The mean diameter of right coronary artery in the present study was found to be $2.83 \mathrm{~mm}$. which is very much approximating with result of study of Bhimalli et al [5].

Mean diameter of ostium of left coronary artery ranged from 3.17-5 $\mathrm{mm}$. in various studies conducted across the world. The mean diameter of left coronary artery in the present study was found to be $3.31 \mathrm{~mm}$. which is very much approximating with result of study of Bhimalli et al [5].

The relative position of coronary ostia in relation to supravalvular ridge is very much important clinically. Small sized coronary ostia cause significant difficulty in canulation of it during various diagnostic as well as therapeutic coronary procedures. The potential clinical disadvantage of this high origin of the coronary orifices lying above the supravalvular ridge is myocardial ischaemia and sudden death. Displacement and oblique course of coronary artery through the aortic wall introduces the potential for luminal narrowing, and may provoke disturbances in myocardial perfusion. Coronary blood flow may be affected by changes in diameter, position and anatomic relations of coronary ostia [2].

Coronary ostia may lie below, at or above the supravalvular ridge. Several studies conducted across the world show variations in position of coronary ostia in relation to supravalvular ridge. Most of the times, ostium of right coronary artery lies below the supravalvular ridge, the incidence noted varies between $60 \%-90 \%$ of the specimens studied in different places. In the present study, in $96 \%$ of specimens of right coronary artery ostium was found to be situated below supravalvular ridge, which is similar to the results of studies by Kalpana et al ${ }^{3}$, Bhimalli et $\mathrm{al}^{5}$ and Dalbir Kaur et al [4]. This similarity can be attributed to geographical factor as all these studies are from various parts of India.

In very few specimens, ostium are located at or above supravalvular ridge, ranging from $10 \%$ $40 \%$ of the specimens studied. Out of these two locations, more number of coronary ostia are located at supravalvular ridge as compared to those above it. This corroborates with the present study in which $4 \%$ of the ostia of right coronary artery are at supravalvular ridge while none are found to be present above it.

While comparing position of ostia of left coronary artery in different studies conducted across the world, the majority of these coronary ostia were found to be located below supravalvular ridge. It ranged from $78 \%-98 \%$ in different studies. In the present study, $100 \%$ of the ostia of left coronary artery were found to be located below supravalvular ridge.

In the study conducted by Cavalcanti et al [7], the ostia of left coronary artery below, at and above supravalvular ridge were found to be $42 \%$, $18 \%$ and $40 \%$ respectively which is differing remarkably from results of other studies. 
Table 9: Table Showing Comparison of Location of Ostia of Right \& left Coronary Artery (In Percentage).

\begin{tabular}{|c|c|c|c|c|c|c|}
\hline \multirow{2}{*}{ Studies } & \multicolumn{3}{|c|}{ Right Coronary Artery } & \multicolumn{3}{c|}{ Left Coronary Artery } \\
\cline { 2 - 7 } & Below SVR & At SVR & Above SVR & Below SVR & At SVR & Above SVR \\
\hline Cavalcanti et al [7] & 60 & 12 & 28 & 42 & 18 & 40 \\
\hline Kalpana et al [3] & 90 & 9 & 1 & 80 & 20 & 0 \\
\hline Bhimalli et al [5] & 84 & 16 & 0 & 93 & 6.66 & 3.33 \\
\hline Dalbir Kaur et al [4] & 83 & 14 & 3 & 78 & 15 & 7 \\
\hline Dombe et al [8] & -- & -- & -- & 79.7 & 17.2 & 3.1 \\
\hline Present Study & 96 & 4 & 0 & 100 & 0 & 0 \\
\hline
\end{tabular}

\section{CONCLUSION}

The present study describes the normal and variant anatomy of the coronary ostia in population of Kolhapur region of Maharashtra. It provides a basis for understanding the normal variants, for determining the incidence of anomalies and for evaluating the value of screening for such anomalies.

The advances made in coronary arterial bypass surgeries and modern methods of myocardial revascularization makes it imperative to have thorough sound and complete knowledge of the normal and variant anatomy of the coronary arteries and its circulation, especially its origin. This led us to the present study. On occasion normal variants, such as multiple ostia, vertical or circumferential shift in position and slit-like ostia may confuse interpretation of the images and may pose a difficulty during procedures such as angiography, angioplasty and coronary artery bypass grafting. During open heart surgeries, it is very difficult to canulate these vessels which arise from the anomalous ostia. While performing coronary arteriography and angiography, a preliminary aortic root injection of the dye must be given to locate the exact number of orifices and coronary arteries so that fatal outcomes can be prevented. The knowledge of the existence of such multiple ostia is important to correctly interprete the angiographic findings.

\section{Conflicts of Interests: None}

\section{REFERENCES}

[1]. Taylor AJ, Byers JP, Cheitlin MD and Virmani R. Anomalous right or left coronary artery from the contralateral coronary sinus:"high risk" abnormalities in the initial coronary artery course and heterogenous clinical outcome. Am. Heart J.1997; 133:428-35.

[2]. Gittenberder-de Groot AC, Sauer U, Quaegebeur J. Aortic intramural coronary artery in three hearts with transposition of great arteries. J Thorac Cardiovasc Surg 1986; 91:566-71.

[3]. Dr. Gourav Dadarao Thakre, Dr. Vaishali V. Inamdar , Dr. Deepak S. Joshi. Variation in number \& diameter of coronary artery ostia: a combined gross anatomical \& angiographic study. IOSR Journal of Dental and Medical Sciences (IOSR-JDMS) .Volume 16, Issue 5 Ver. XI (May. 2017);08-11.

[4]. Dr Dalbir Kaur, Dr Karandeep Singh, Dr Narga Nair, Amandeep Singh Kalra. Morphology and morphometry of coronary ostia in south indian adult human cadaveric hearts. International Journal of Biological And Medical Research. 2012 3(3) 2169-2171.

[5]. Shilpa Bhimalli, Daksha Dixit, Mahantesh Siddibhavi and V S Shirol. A study of variations in coronary arterial system in cadaveric human heart. World Journal of Science and Technology. 2011, 1(5): 3035.

[6]. Cavalcanti JS, de Melo NC, de Vasconcelos RS., Morphometric and topographic study of the coronary ostia. Arq Bras Cardiol. 2003;81(4):359362.

[7]. Cavalcanti JS, de Lucena Oliveira M, Pais e Melo AV Jr., Balaban G, de Andrade Oliveira CL, de Lucena Oliveira E. Anatomic variations of the coronary arteries. Arq Bras Cardiol. 1995 Dec;65(6):489-492.

[8]. Dattatray D. Dombe, Takkallapalli Anitha, Purushottam A. Giri, Swapnali D. Dombe, Medha V. Ambiye. Clinically relevant morphometric analysis of left coronary artery. Int J Biol Med Res. 2012; 3(1): 1327-1330.

How to cite this article:

Dakhane Prafulla S, Patil Tushar R. STUDY OF CORONARY OSTIA IN PRESERVED HUMAN CADAVERIC HEART SPECIMENS IN WESTERN MAHARASHTRA BY DISSECTION METHOD. Int J Anat Res 2018;6(3.1):5400-5404. DOI: 10.16965/ijar.2018.216 